\title{
The impact of thermal reprocessing of 3D printable polymers on their mechanical performance and airborne pollutant profiles
}

\author{
Antti Juho Kalevi Väisänen ${ }^{1,2}$ (1) $\cdot$ Lauri Alonen ${ }^{2} \cdot$ Sampsa Ylönen $^{2} \cdot$ Isa Lyijynen $^{3} \cdot$ Marko Hyttinen $^{1}$
}

Received: 18 June 2021 / Accepted: 17 August 2021 / Published online: 26 October 2021

(c) The Author(s) 2021

\begin{abstract}
The alterations in volatile organic compound (VOC) and ultrafine particulate (UFP) matter emission profiles following thermal reprocessing of multiple materials were examined. Additionally, mechanical performance of the materials was studied. The VOCs were identified by collecting air samples with Tenax ${ }^{\circledR}$ TA tubes and analyzing them with a GC-MS system. UFP concentrations were monitored with a portable ultrafine particle counter. Total VOC emissions of all materials were reduced by $28-68 \%$ after 5 thermal cycles (TCs). However, slight accumulation of 1,4-dioxane was observed with poly(lactic acid) materials. UFP emissions were reduced by $45-88 \%$ for $3 \mathrm{D}$ printing grade materials over 5 TCs but increased by $62 \%$ in the case of a waste plastic material over 3 TCs. The mechanical performance of the materials was investigated by measuring their tensile strengths (TSs) and elastic moduli (EM) with an axial-torsion testing system. The reprocessed materials expressed fluctuations in their 3D printing qualities and mechanical performances. The mechanical performances were observed to reduce only slightly after $5 \mathrm{TCs}$, and the trend was observable only after the data was mass-normalized. The TSs of the samples were reduced by 10-24\%, while the EM were reduced by 1-9\% after 5 TCs. The TS and EM of one material were increased by 14 and 33\%, respectively. In conclusion, recycled polymers are plausible 3D printing feedstock alternatives as they possess acceptable mechanical performance and low emittance according to this study. Furthermore, non-3D printing grade polymers may be applied in a 3D printer with caution.
\end{abstract}

Keywords Additive manufacturing $\cdot$ Tensile strength $\cdot$ Plastics $\cdot$ Thermal treatment $\cdot$ Volatile organic compounds

\section{Introduction}

The environmental impacts of plastics and demands for effective recycling measures have been recent topics of intensive debate. These issues call for new innovative solutions, of which one is the sustainable use of plastic materials. The 3D printing industry is another source - or a potential consumer - of waste plastics. Failed 3D printed objects typically end up in waste disposal as the object is ruined and cannot be used either for its designed purpose or as a

Antti Juho Kalevi Väisänen

antti.vaisanen@uef.fi

1 Faculty of Science and Forestry, Department of Environmental and Biological Sciences, University of Eastern Finland, Kuopio, Finland

2 School of Engineering and Technology, Savonia University of Applied Sciences, Kuopio, Finland

3 Faculty of Science and Forestry, Department of Applied Physics, University of Eastern Finland, Kuopio, Finland feedstock material for a new 3D print job attempt. However, novel and inexpensive 3D printing filament extruders which are capable of producing 3D printable filaments out of plastic scrap materials have been introduced into the consumer markets over the past years. These devices can increase the small-scale recycling of plastics. They can make use of failed 3D prints and household waste plastics (HWPs) in 3D printer feedstock filament production. Additionally, the first 3D printing material producers have entered the recycled feedstocks market.

Thermal degradation of polymers is a phenomenon that occurs when a polymer (plastic) is exposed to sufficiently high temperatures, and physical or chemical stress [1-3]. Polymer chains undergo chain scission and low molecularweight compounds, including property enhancing additives, are disintegrated from the base polymer bulk. The leftover polymer bulk becomes increasingly shorter, lighter, fragile, $[1,2,4]$ and too intractable to apply in a 3D printer [5]. Additionally, polymers can suffer from water-induced hydrolysis and thermo-oxidative degradation when exposed 
to air, which results in further chemical decomposition [2]. Cross-linking is another common physiochemical occurrence in which additional bonds are formed inside a base polymer bulk. Cross-linking hardens the polymer substantially, resulting in a hard but brittle polymer structure [1, $2,4,6,7]$. These alterations in the polymer structure affect the mechanical performance of a recycled material $[3,6]$. The main factors which affect the level and the mechanism of degradation during thermal treatment are the processing temperature and the presence of oxygen and other catalysts $[1,2,5,6]$. Thermal degradation results in reductions in the mass and the density of the polymer. These factors are major determinants of the tensile strength (TS) of a material $[2,8]$. Mechanical performance is impaired in tandem with polymer chain transformations, up until a point where the material is no longer reprocessable [5]. Furthermore, the 3D printing parameters, e.g. printing temperature, infill ratio, and pattern, all affect the physical features, and layer-to-layer adhesion of the 3D printed object. These factors, in addition to polymer filament integrity, all have a significant impact on the mechanical properties of the printed object [8-12].

The emissions of material extrusion 3D printing with the most common polymer types have been extensively studied. However, the impact that thermal reprocessing has on the emissions and the mechanical properties of polymers has not been documented as comprehensively. The thermal processing of polymers is a known source of volatile organic compounds (VOCs). These compounds consist of a carbon skeleton and may carry bound functional groups [13-19]. The typical organic compounds emitted in a polymer decomposition process are short, usually 2 to 8 carbon atoms in length, and capable of attaching to airborne particles $[2,7$, 20]. In addition, 3D printing has been documented to be an emission source for ultrafine particles (UFPs) which are formed through polymer chain decomposition and the condensation of VOCs [13-16, 18, 19, 21-24]. VOCs and UFPs both have the potency for adversely affecting human health through the promotion of lung diseases and the induction of oxidative stress, irritation, inflammation, sensitization, influences in the central nervous system (CNS) and skin effects. These exposure agents are ultimately recognized as the main health hazards of 3D printing [25-33].

Thermal reprocessing of polymers has been found to result in lower total VOC (TVOC) emissions during subsequent extrusion processes. This is a result of the most readily volatilized compounds disintegrating from a polymer chain during the initial extrusion processes. Less volatile chemical structures persist, and thus the TVOC emissions are reduced during thermal reprocessing [20,34]. The applied temperature, the presence of oxygen and other reactive compounds and the polymer base are the main factors affecting the formed degradation products. Higher temperatures drive the degradation products towards compounds with larger molecular mass. Oxygen is highly reactive with alkyl compounds, resulting in the production of oxygenated hydrocarbons, e.g., aldehydes and acids. The polymer base ultimately determines the possible off-gassed emission profile [1-3, 20]. The accumulation of certain compounds and impurities, e.g., dioxanes, has been reported along with the overall reduction of the TVOC emissions over repetitive thermal reprocessing [20,34]. The accumulation and the volatilization of impurities and pollutants is a major health concern regarding HWP filament application. Unknown additives which improve the desired properties of a plastic may have been used in the polymer production. Additionally, residues of food or consumer chemicals may be present in or absorbed into the polymer structure [34]. Thermal processing of such contaminated plastics is a potential source of unpredicted chemical emissions, which may possess harmful characteristics. Exposure to these emissions can lead to adverse health outcomes which are difficult to predict. In addition, the additives used in HWPs are likely to differ from the ones used in $3 \mathrm{D}$ printing grade plastics. Henceforth, the $3 \mathrm{D}$ printability and the mechanical performance of the products 3D printed with HWP plastics may be unsatisfactory.

Thermal reprocessing of plastics has been recorded to reduce the TS of the material. Elastic modulus (EM) has not been found to follow a similar pattern, as the modulus has been recorded to fluctuate from increasing to decreasing over the course of multiple thermal treatment cycles [5, 34]. The alteration of mechanical properties of reprocessed plastics is of interest in the 3D printing industry, as it could be a consumer of recycled plastics. However, the objects produced from recycled plastics should express adequate mechanical properties and processability to be applicable in real-life situations. Additionally, safety aspects regarding the application of thermally reprocessed materials must be evaluated before such materials are applied by $3 \mathrm{D}$ printer operators.

The main goal of this study was to observe how the VOC and UFP profiles of multiple plastic materials alter after repetitive thermal reprocessing. The gathered results are used to estimate the safety aspects of thermally reprocessed plastics when applied in a 3D printer. A secondary objective was to examine the alteration of mechanical performance of 3D printed objects fabricated from thermally reprocessed materials. A joint goal of this study was to find justifications for the application of recycled materials over virgin polymers in the $3 \mathrm{D}$ printing industry.

\section{Materials and methods}

The VOC and UFP emission concentrations were measured during 3D printing of ASTM D638 type IV tensile test specimens. These pollutants were selected because they have been 
identified as the main emission products originating from material extrusion 3D printing [13-19, 21-24]. The tensile test specimens with a calculated volume of $6.22 \mathrm{~cm}^{3}$ were fabricated by applying 0/90-degree printing angle, $100 \%$ infill and feed rates, $0.2 \mathrm{~mm}$ layer thickness, and $0.4 \mathrm{~mm}$ path width. The pollutant concentrations were measured during printing with virgin and from one to five times thermally reprocessed materials. TS and EM were measured from virgin materials and after one to five thermal reprocessing cycles of every filament type. All the used equipment were factory and/or zero calibrated accordingly before sample collection and material property testing.

Four filament types were used in this study: ReForm rPLA (Formfutura B.V., Nijmegen, Netherlands, made from extrusion waste stream plastic, density $1.24 \mathrm{~g} / \mathrm{cm}^{3}$, subsequently referred to as PLA ReForm), Premium PLA Robotic Grey (Formfutura B.V., density $1.24 \mathrm{~g} / \mathrm{cm}^{3}$, subsequently referred to as PLA Robotic Gray), Natural Transparent PP Filament (Verbatim Corp., Tokyo, Japan, density $0.89 \mathrm{~g} /$ $\mathrm{cm}^{3}$, subsequently referred to as PP Transparent) and PP waste plastic filament produced from water-washed PP bottle caps (density unknown, subsequently referred to as PP HWP). The materials applied in this study represent environmentally friendly and readily available plastic types. PLA was chosen based on its renewable origin and wide application in the 3D printing industry, while PP was chosen because it is an abundant commodity plastic used widely among different industries, including as a packaging material. A SHR3D IT plastic shredder (3devo B.V., Utrecht, Netherlands) and a Composer 450 filament extruder (3devo B.V.) with four temperature-adjustable heating zones were used in filament reproduction. The study was performed by manufacturing three parallel tensile specimens with each filament. The leftover filament bulk was shredded, a new filament was extruded from the produced filament bits, and additional tensile specimens were printed with the reprocessed filament, and so forth. The PP HWP bottle caps were initially shredded and extruded into the form of a filament, whereafter it underwent similar processing procedure. The shredder was cleaned with pressurized air after each shredding process to prevent cross-contamination of the materials.

Eri Keeper glue (Oy Sika Finland Ab, Espoo, Finland) and generic PP packaging tape were, respectively, used to enhance the adhesion of PLA and PP materials to the 3D printing platform. For temperature settings applied during 3D printing and filament production, see the Table 1 . A ZMorph 2.0 SX material extrusion 3D printer (ZMorph S.A., Wroclaw, Poland) with a $0.4 \mathrm{~mm}$ print head was operated in this study under laboratory conditions. The research area with a volume of $256 \mathrm{~m}^{3}$ was mechanically ventilated. The space was ventilated after each print job and the clearance of pollutants was verified by the reduction of UFP concentration down to the background level. The space was ventilated for an additional hour to ensure the absence of pollutants. The duration of each individual printing process was approx. $150 \mathrm{~min}$.

\section{Exposure agent measurements}

Blank and background VOC and UFP samples were collected before 3D printing was initiated. The two classes of pollutants were individually measured from two successive print jobs to prevent the VOC sampling from being affected by the emission of isopropyl alcohol released during the UFP sampling.

The VOCs were collected with Tenax ${ }^{\circledR}$ TA adsorption tubes (Markes Inc., Sacramento, CA) containing $200 \mathrm{mg}$ of sorbent, and AirChek 3000 pumps (SKC Inc., Eighty Four, PA) calibrated with a mini-BUCK Calibrator (A. P. BUCK Inc., Orlando, FL). Three consecutive samples were collected over each 3D print job from the beginning, middle and end phases of the print job. The samples were collected from the altitude of the breathing zone (approx. $1.5 \mathrm{~m}$ ) and a close proximity of the printer (approx. distance $1 \mathrm{~m}$ ). The collection time for an individual sample was $20 \mathrm{~min}$. The samples were analyzed according to the ISO-16000 standard method. A TD100 thermal desorber (Markes Inc.), a 7890A gas chromatography system with an HP5ms column (50 m length and $200 \mu \mathrm{m}$ film thickness, Agilent Technologies Inc., Santa Clara, CA) and a 5975C mass spectrometer (Agilent Technologies Inc.) were used for the sample analysis. The results were background and blank corrected. Furthermore, the VOCs released from the adhesives were analyzed and subtracted from the presented VOC results. Four-point standard curves were produced from an HC 48 component 40,353-U standard solution (Supelco Inc., Bellefonte, PA). The mass spectrometer was operated under SCAN mode to allow the identification of all compounds captured in the Tenax $₫$ sampling tubes. Every compound which was detected in at least 2 of the 3 consecutive samples were included in the results. This procedure reduced results bloat and disregarded certain compounds which were not formed in abundance during the 3D printing processes. An MSD ChemStation program version F.01.00.1903 (Agilent Technologies Inc.) was used for the compound identification. The limit of detection of an individual compound was the exceeding of the background noise by fivefold. The compound concentrations were calculated as toluene equivalents. For additional details, please see the preliminary study [19].

The UFPs were monitored with a P-Trak Ultrafine Particle Counter 8525 instrument (TSI Inc., Shoreview, MN) over the complete $3 \mathrm{D}$ printing jobs. The UFP samples were collected from the same location as the VOC samples. The presented results are corrected by the background UFP concentration. The ISO/ASTM CD 52,932 standard for $3 \mathrm{D}$ printing emission rate analysis was not yet published 
Table 1 3D Printing and filament production specifications

\begin{tabular}{llll}
\hline Filament Type & 3D Printing temperatures & Adhesive & $\begin{array}{l}\text { Filament production } \\
\text { temperatures }\end{array}$ \\
\hline PLA Robotic Gray & $205^{\circ} \mathrm{C}$ nozzle, $60{ }^{\circ} \mathrm{C}$ bed & Glue & $200 / 215 / 195 / 190{ }^{\circ} \mathrm{C}$ \\
PLA ReForm & $205{ }^{\circ} \mathrm{C}$ nozzle, $60^{\circ} \mathrm{C}$ bed & & $200 / 210 / 190 / 185^{\circ} \mathrm{C}$ \\
PP Transparent & $230{ }^{\circ} \mathrm{C}$ nozzle, $85{ }^{\circ} \mathrm{C}$ bed & Packaging tape & $205 / 215 / 190 / 185^{\circ} \mathrm{C}$ \\
PP HWP & $235{ }^{\circ} \mathrm{C}$ nozzle, $90{ }^{\circ} \mathrm{C}$ bed & & $220 / 225 / 215 / 195{ }^{\circ} \mathrm{C}$ \\
\hline
\end{tabular}

when the samples were collected, thus the sampling was performed at the vicinity of the 3D printer, similarly to the preliminary study [19].

\section{Material property measurements}

The tensile specimens were tested according to the ASTM D638 standard with an Instron 8874 universal axial-torsion testing system (Instron Corp., High Wycombe, UK) by applying $4 \mathrm{~mm} / \mathrm{min}$ pulling speed under normal room temperature and conditions. Three parallel specimens were used in every test. The TS and EM were derived from the produced stress-strain curve. A MATLAB program version R2016b (Mathworks Corp., Brentwood, CA) was used to analyze the mechanical properties by plotting the relative strain in accordance with the relative stress. EM was derived from the slope of a fitted least squares function in the linear area of the curve. TS was derived from the peak Y-axis value (applied force in Newtons). Dimensions of the specimens were measured with a QuantuMike IP65 caliper (Mitutoyo Corp., Kawasaki, Japan) and weighed with an AC100 scale (Mettler Toledo Inc.).

\section{Results}

\section{Exposure agent measurement results}

The initial TVOC emissions were relatively low [29] during printing with all tested materials and the measured concentrations decayed further after each successive thermal cycle (TC), as seen in the Fig. 1. The steepest reduction was detected between the virgin and once reprocessed materials. Thereafter the reducing effect was notably lower and most readily detected with the PLA materials. Additionally, the virgin PLA materials were slightly higher VOC emitters than the virgin PP filaments, but the TVOC levels evened out after one TC. The TVOC values were reduced by $62-68 \%$ over 5 TCs for the PLA materials and by $28-48 \%$ for the PP materials. The full VOC profiles are presented in the Supplementary Tables 1 and 2 .

The concentrations of the most prevalent individual VOCs measured during 3D printing with PLA materials were the same for both filaments. The concentrations of the individual compounds followed a similar reducing trend as the TVOC concentrations did, as seen in the Figs. 2 and 3.
Fig. 1 TVOC concentrations and standard deviations measured from 3D printing with virgin and thermally reprocessed filaments
Total VOCs

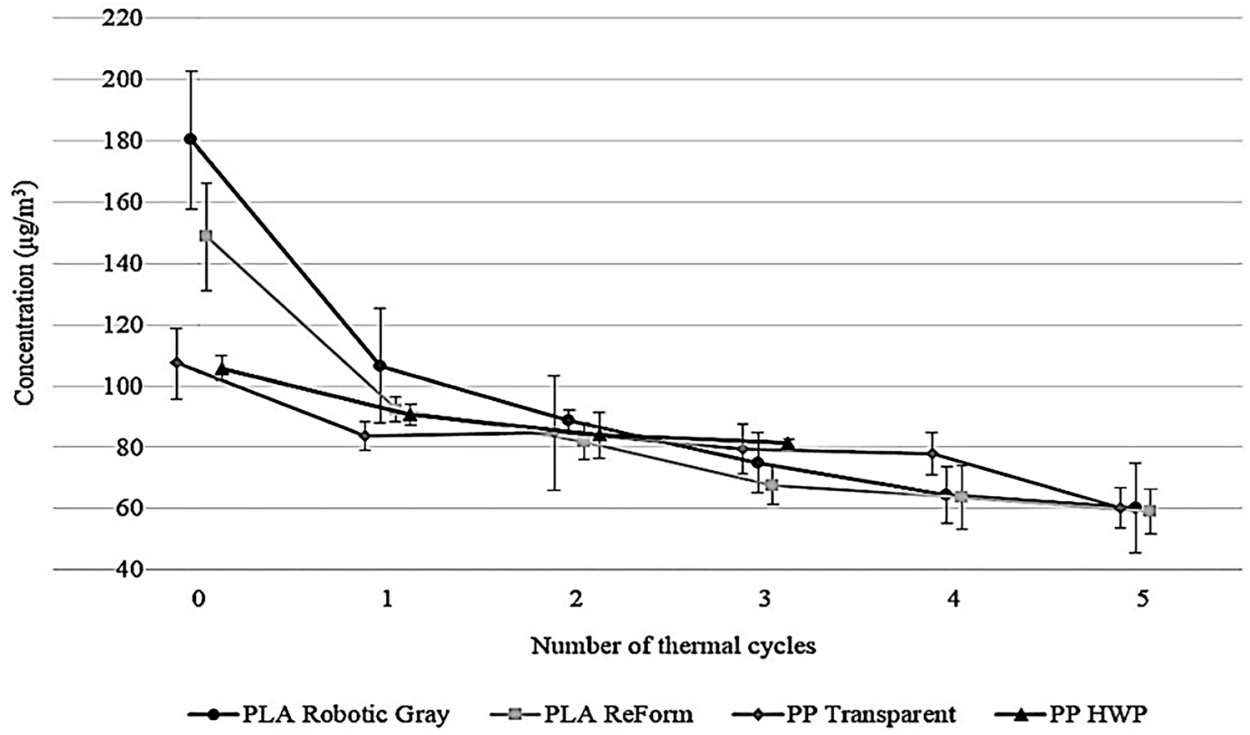


One compound, 1,4-dioxane, portrayed a reverse behavior. It was not detected during printing with the virgin materials but was eventually found at increasing concentrations during printing with all the reprocessed PLA materials. Additionally, the number of individual compounds reduced as the number of TCs increased.

Similar reduction of the VOC emissions was observed during 3D printing with the thermally reprocessed PP filaments as well, but to a lesser extent. The effect was least notable with the PP HWP material. No observable accumulation of any single compound was detected, even though 3D printing with the PP HWP material was expected to raise the highest concerns. The most prevalent VOCs released during printing with the PP filaments are presented in the Figs. 4 and 5. Propylene glycol was the only actual detected outlier compound, but certain compounds could be confined as the other main emission products and are therefore presented in the figures.

Similarly to the TVOC concentration reduction, lower concentrations of UFPs were emitted during printing with reprocessed filaments with the most materials. The PP HWP material was an exception and a contrary trend was found, as seen in the Fig. 6. This odd behavior can be explained with the polymer grade, as the PP HWP material was a molding grade polymer rather than a $3 \mathrm{D}$ printing grade one. Therefore, no 3D printability enhancing additives were present in the material. Overall, the UFP emissions were very low, except during printing with thermally reprocessed PP HWP filament. The measured concentrations were up to 100-fold in comparison to the least UFP emitting PLA material. Still, the concentrations were relatively low in comparison to the proposed occupational lightweight UFP reference value of

Table 2 Material properties of 3D printed specimens

\begin{tabular}{|c|c|c|c|c|c|c|c|c|}
\hline \multicolumn{9}{|c|}{ Polymer grade: PLA } \\
\hline \multicolumn{4}{|c|}{ PLA Robotic Gray } & \multicolumn{3}{|c|}{ PLA ReForm } & \multicolumn{2}{|c|}{$\begin{array}{l}\text { Pooled PLA reference } \\
\text { data }^{(9-12,36-38)}\end{array}$} \\
\hline Sample & $\begin{array}{l}\text { Tensile Strength } \\
(\mathrm{MPa})\end{array}$ & $\begin{array}{l}\text { Elastic Modulus } \\
\quad(\mathrm{GPa})\end{array}$ & Mass (g) & $\begin{array}{l}\text { Tensile Strength } \\
\text { (MPa) }\end{array}$ & $\begin{array}{l}\text { Elastic Modulus } \\
\quad(\mathrm{GPa})\end{array}$ & Mass (g) & $\begin{array}{l}\text { Tensile Strength } \\
(\mathrm{MPa})\end{array}$ & $\begin{array}{l}\text { Elastic Modulus } \\
\quad(\mathrm{GPa})\end{array}$ \\
\hline Virgin & $\begin{array}{l}54.3 \pm 0.7 \\
(53.5-54.7)\end{array}$ & $\begin{array}{l}1.97 \pm 0.08 \\
(1.88-2.04)\end{array}$ & $\begin{array}{l}7.63 \pm 0.03 \\
(7.60-7.66)\end{array}$ & $\begin{array}{l}47.5 \pm 1.1 \\
(46.3-48.3)\end{array}$ & $\begin{array}{l}1.86 \pm 0.05 \\
(1.81-1.91)\end{array}$ & $\begin{array}{l}7.43 \pm 0.07 \\
(7.35-7.49)\end{array}$ & $\begin{array}{l}49.1 \pm 10.3 \\
(28.4-65.5)\end{array}$ & $\begin{array}{l}3.36 \pm 0.52 \\
(2.66-4.26)\end{array}$ \\
\hline TC 1 & $\begin{array}{l}41.8 \pm 1.1 \\
(40.9-43.0)\end{array}$ & $\begin{array}{l}1.72 \pm 0.02 \\
(1.71-1.74)\end{array}$ & $\begin{array}{l}6.73 \pm 0.03 \\
(6.71-6.76)\end{array}$ & $\begin{array}{l}40.5 \pm 0.8 * \\
(39.9-41.0)\end{array}$ & $\begin{array}{l}1.69 \pm 0.01 * \\
(1.68-1.69)\end{array}$ & $\begin{array}{l}6.88 \pm 0.03 \\
(6.85-6.91)\end{array}$ & $35.9 \pm 0.3$ & $4.03 \pm 0.50$ \\
\hline $\mathrm{TC} 2$ & $\begin{array}{l}44.1 \pm 2.3 * \\
(42.4-45.7)\end{array}$ & $\begin{array}{l}1.78 \pm 0.06^{*} \\
(1.74-1.82)\end{array}$ & $\begin{array}{l}6.30 \pm 0.05 \\
(6.26-6.34)\end{array}$ & $\begin{array}{l}30.7 \pm 0.9 \\
(29.7-31.2)\end{array}$ & $\begin{array}{l}1.44 \pm 0.04 \\
(1.41-1.48)\end{array}$ & $\begin{array}{l}5.88 \pm 0.07 \\
(5.70-5.93)\end{array}$ & - & - \\
\hline TC 3 & $\begin{array}{l}45.9 \pm 1.5 \\
(44.2-47.2)\end{array}$ & $\begin{array}{l}1.79 \pm 0.02 \\
(1.77-1.81)\end{array}$ & $\begin{array}{l}7.10 \pm 0.03 \\
(7.08-7.13)\end{array}$ & $\begin{array}{l}40.4 \pm 1.2 \\
(39.4-41.8)\end{array}$ & $\begin{array}{l}1.68 \pm 0.11 \\
(1.61-1.81)\end{array}$ & $\begin{array}{l}7.41 \pm 0.04 \\
(7.37-7.44)\end{array}$ & - & - \\
\hline $\mathrm{TC} 4$ & $\begin{array}{l}38.1 \pm 0.9 \\
(37.3-39.1)\end{array}$ & $\begin{array}{l}1.54 \pm 0.07 \\
(1.47-1.61)\end{array}$ & $\begin{array}{l}7.02 \pm 0.04 \\
(6.99-7.07)\end{array}$ & $\begin{array}{l}38.7 \pm 1.1 \\
(37.5-39.8)\end{array}$ & $\begin{array}{l}1.55 \pm 0.03 \\
(1.52-1.57)\end{array}$ & $\begin{array}{l}7.12 \pm 0.10 \\
(7.01-7.21)\end{array}$ & - & - \\
\hline TC 5 & $\begin{array}{l}43.1 \pm 0.6 \\
(42.4-43.6)\end{array}$ & $\begin{array}{l}1.69 \pm 0.06 \\
(1.64-1.75)\end{array}$ & $\begin{array}{l}7.23 \pm 0.06 \\
(7.20-7.31)\end{array}$ & $\begin{array}{l}43.1 \pm 1.8 \\
(41.7-45.1)\end{array}$ & $\begin{array}{l}1.80 \pm 0.04 \\
(1.77-1.84)\end{array}$ & $\begin{array}{l}7.50 \pm 0.06 \\
(7.45-7.57)\end{array}$ & - & - \\
\hline \multicolumn{9}{|c|}{ Polymer grade: PP } \\
\hline \multicolumn{4}{|c|}{ PP Transparent } & \multicolumn{3}{|c|}{ HWP-PP } & \multicolumn{2}{|c|}{$\begin{array}{c}\text { Pooled PP reference } \\
\text { data }^{(39-42)}\end{array}$} \\
\hline Sample & $\begin{array}{l}\text { Tensile Strength } \\
(\mathrm{MPa})\end{array}$ & $\begin{array}{l}\text { Elastic Modulus } \\
\quad(\mathrm{GPa})\end{array}$ & Mass (g) & $\begin{array}{l}\text { Tensile Strength } \\
(\mathrm{MPa})\end{array}$ & $\begin{array}{l}\text { Elastic Modulus } \\
\quad(\mathrm{GPa})\end{array}$ & Mass (g) & $\begin{array}{l}\text { Tensile Strength } \\
(\mathrm{MPa})\end{array}$ & $\begin{array}{l}\text { Elastic Modulus } \\
\quad(\mathrm{GPa})\end{array}$ \\
\hline Virgin & $\begin{array}{l}14.3 \pm 0.5 \\
(13.8-14.9)\end{array}$ & $\begin{array}{l}0.24 \pm 0.00 \\
(0.24)\end{array}$ & $\begin{array}{l}5.28 \pm 0.02 \\
(5.27-5.30)\end{array}$ & $\begin{array}{l}21.4 \pm 2.0 \\
(19.0-22.8)\end{array}$ & $\begin{array}{l}0.75 \pm 0.01 \\
(0.74-0.75)\end{array}$ & $\begin{array}{l}4.34 \pm 0.26 \\
(4.04-4.49)\end{array}$ & $\begin{array}{l}27.2 \pm 6.0 \\
(21.1-35.5)\end{array}$ & $\begin{array}{l}1.05 \pm 0.22 \\
(0.85-1.25)\end{array}$ \\
\hline $\mathrm{TC} 1$ & $\begin{array}{l}14.4 \pm 0.5 \\
(14.0-14.9)\end{array}$ & $\begin{array}{l}0.28 \pm 0.01 \\
(0.27-0.29)\end{array}$ & $\begin{array}{l}4.62 \pm 0.02 \\
(4.60-4.64)\end{array}$ & $\begin{array}{l}17.8 \pm 0.2 \\
(17.6-18.0)\end{array}$ & $\begin{array}{l}0.72 \pm 0.01 \\
(0.72-0.73)\end{array}$ & $\begin{array}{l}4.34 \pm 0.11 \\
(4.26-4.46)\end{array}$ & $\begin{array}{l}23.6 \pm 2.6 \\
(19.9-27.3)\end{array}$ & $\begin{array}{l}0.89 \pm 0.19 \\
(0.75-1.13)\end{array}$ \\
\hline $\mathrm{TC} 2$ & $\begin{array}{l}14.8 \pm 0.2 \\
(14.6-15.0)\end{array}$ & $\begin{array}{l}0.29 \pm 0.02 \\
(0.28-0.31)\end{array}$ & $\begin{array}{l}4.81 \pm 0.05 \\
(4.76-4.84)\end{array}$ & $\begin{array}{l}19.0 \pm 1.0 * \\
(18.2-19.7)\end{array}$ & $\begin{array}{l}0.77 \pm 0.01 * \\
(0.76-0.78)\end{array}$ & $\begin{array}{l}3.69 \pm 0.13 \\
(3.60-3.81)\end{array}$ & - & - \\
\hline TC 3 & $\begin{array}{l}13.9 \pm 0.4 \\
(13.7-14.3)\end{array}$ & $\begin{array}{l}0.28 \pm 0.01 \\
(0.28-0.29)\end{array}$ & $\begin{array}{l}4.76 \pm 0.04 \\
(4.72-4.79)\end{array}$ & $\begin{array}{l}13.5 \pm 1.2 \\
(12.6-14.8)\end{array}$ & $\begin{array}{l}0.63 \pm 0.01 \\
(0.61-0.64)\end{array}$ & $\begin{array}{l}3.68 \pm 0.07 \\
(3.63-3.76)\end{array}$ & - & - \\
\hline $\mathrm{TC} 4$ & $\begin{array}{l}14.4 \pm 0.1 \\
(14.3-14.5)\end{array}$ & $\begin{array}{l}0.28 \pm 0.02 \\
(0.27-0.30)\end{array}$ & $\begin{array}{l}4.65 \pm 0.03 \\
(4.62-4.67)\end{array}$ & - & - & - & - & - \\
\hline TC 5 & $\begin{array}{l}14.3 \pm 0.2 \\
(14.2-14.5)\end{array}$ & $\begin{array}{l}0.28 \pm 0.01 \\
(0.28-0.29)\end{array}$ & $\begin{array}{l}4.63 \pm 0.03 \\
(4.61-4.66)\end{array}$ & - & - & - & - & - \\
\hline
\end{tabular}

Average value \pm standard deviation of $n=3$ parallel samples. Range shown in brackets. $*=$ Sample size $n=2$ 
Fig. 2 Concentrations and standard deviations of the most prevalent compounds detected during 3D printing with PLA Robotic Gray filament. Number of compounds detected during virgin material printing $=23$ and after $5 \mathrm{TCs}=13$

Fig. 3 Concentrations and standard deviations of the most prevalent compounds detected during 3D printing with PLA ReForm filament. Number of compounds detected during virgin material printing $=22$ and after $5 \mathrm{TCs}=13$

\section{Most prevalent VOCs (PLA Robotic Gray)}

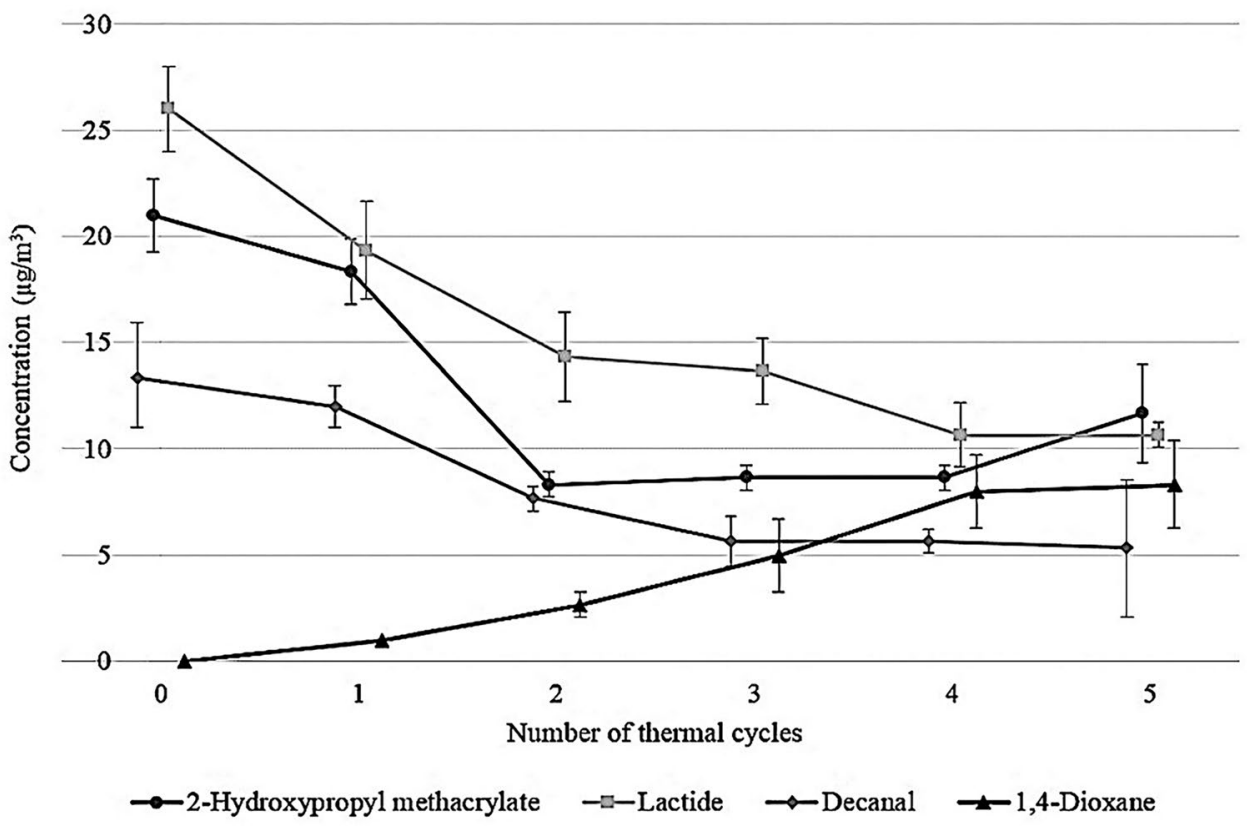

\section{Most prevalent VOCs (PLA ReForm)}

25

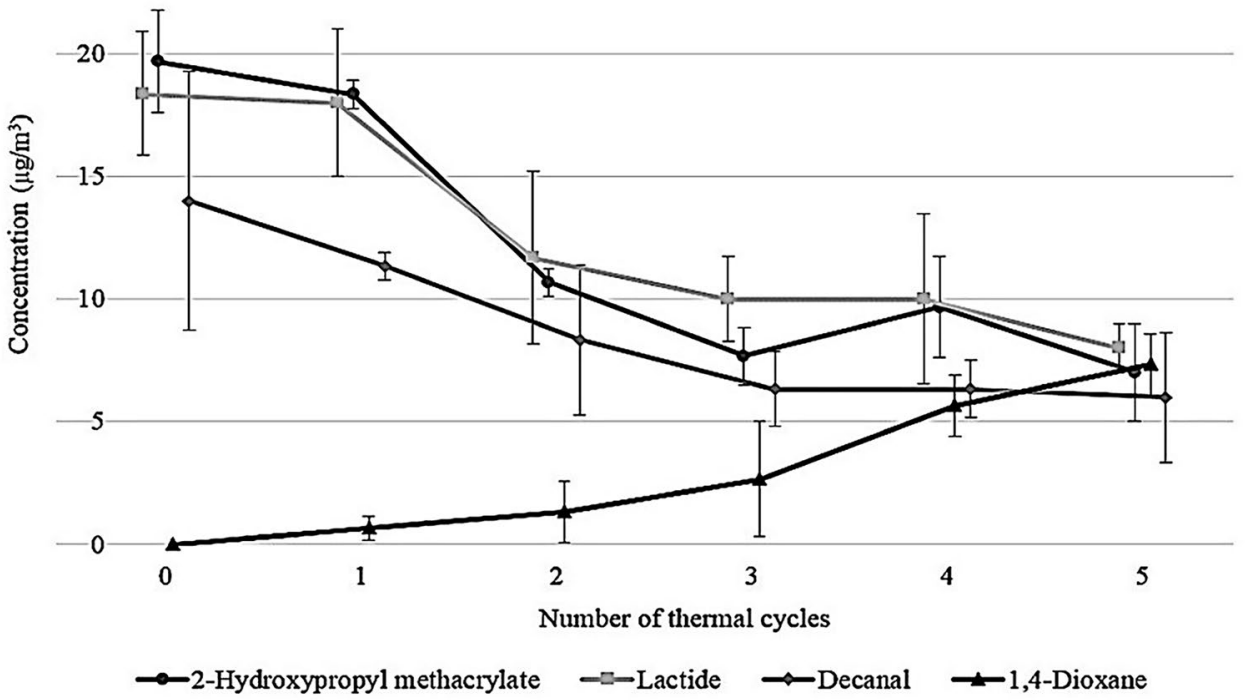


Fig. 4 Concentrations and standard deviations of the most prevalent compounds detected during 3D printing with $\mathrm{PP}$ Transparent filament. Number of compounds detected during virgin material printing $=22$ and after $5 \mathrm{TCs}=16$

Fig. 5 Concentrations and standard deviations of the most prevalent compounds detected during $3 \mathrm{D}$ printing with $\mathrm{PP}$ HWP filament. Number of compounds detected during virgin material printing $=27$ and after $3 \mathrm{TCs}=20$

\section{Most prevalent VOCs (PP Transparent)}

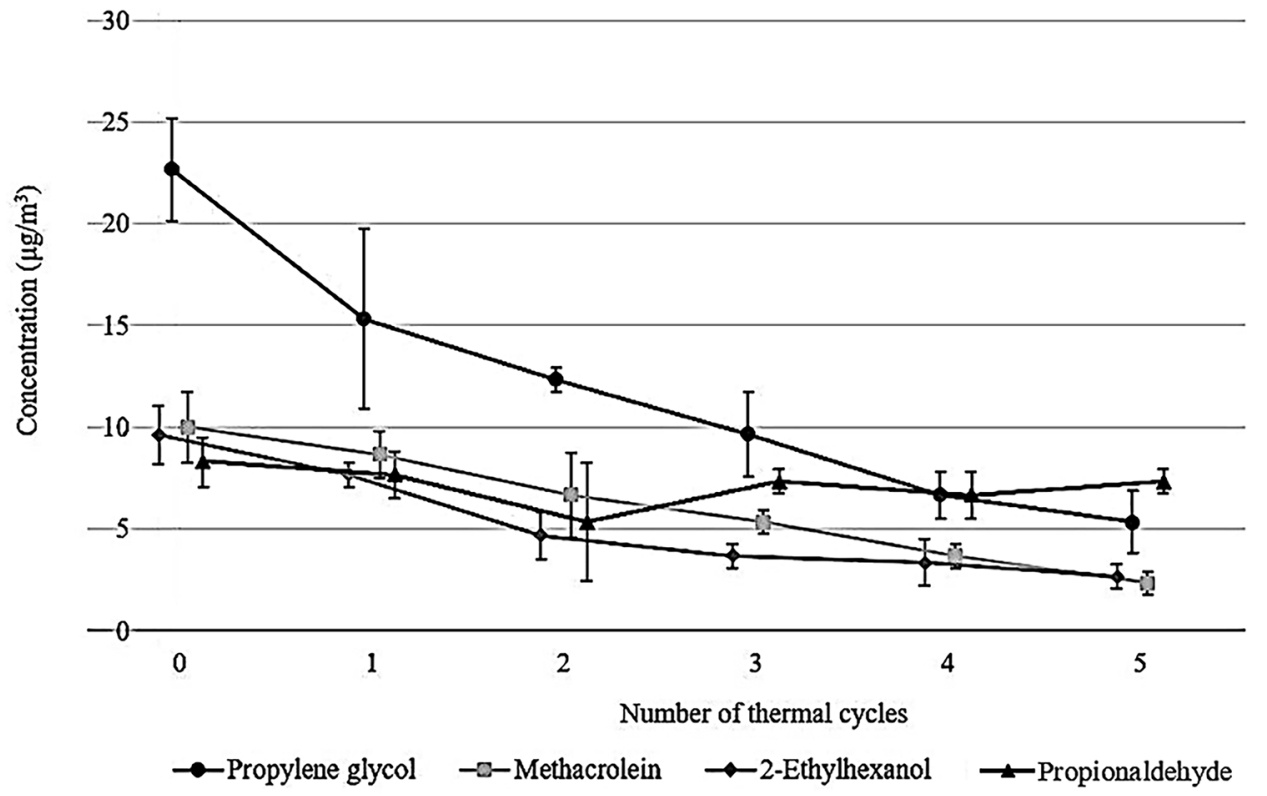

Most prevalent VOCs (PP HWP)

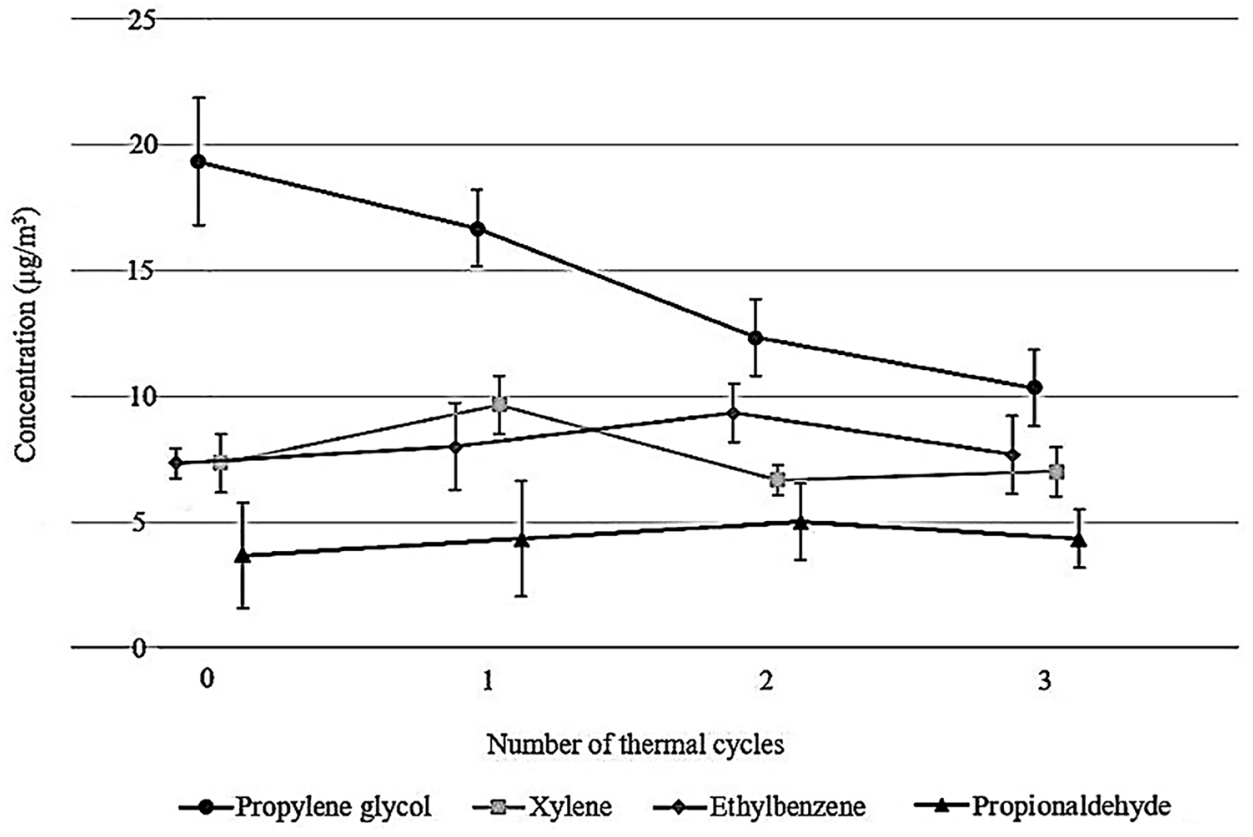


Fig. 6 UFP concentrations and standard deviations measured from $3 \mathrm{D}$ printing with virgin and thermally reprocessed filaments

\section{Ultrafine Particles}

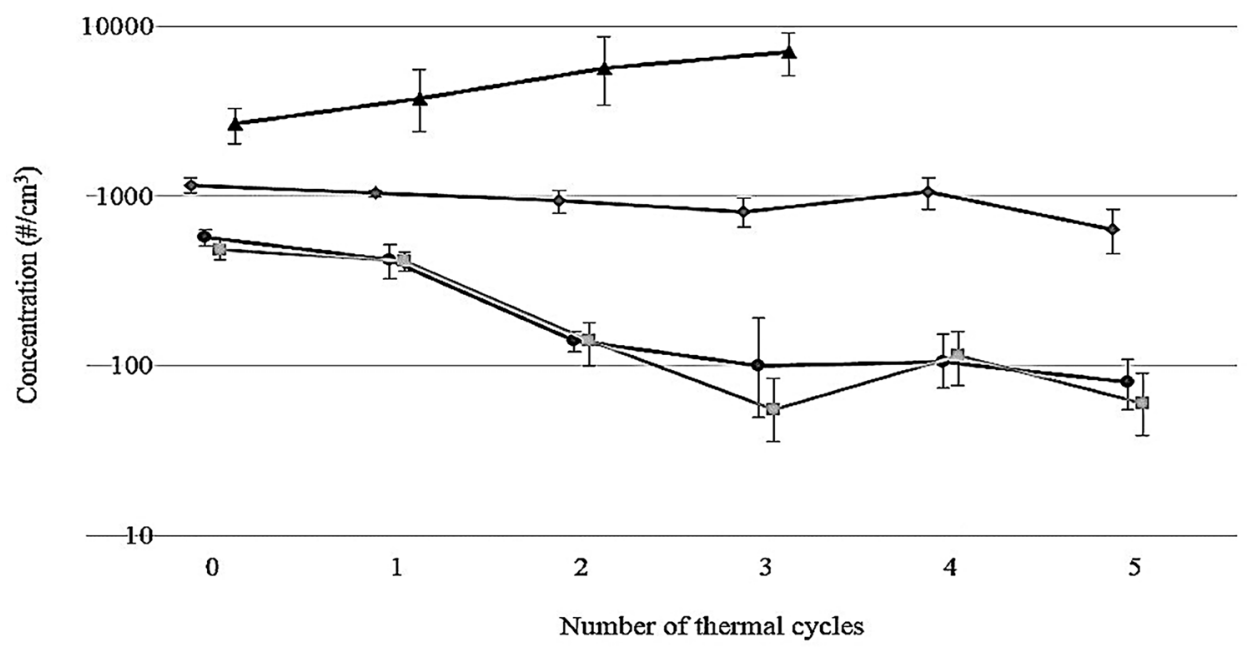

$\rightarrow$ PLA Robotic Gray

$-\square-P L A$ ReForm

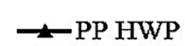

$40,000 \# / \mathrm{cm}^{3}$ [35]. The UFP emissions were reduced by $86-88 \%$ in the cases of the PLA materials, and by $45 \%$ in the case of the PP Transparent material over 5 TCs. The UFP emissions increased by as much as $62 \%$ in the case of the PP HWP material over 3 TCs. Full UFP data is presented in the Supplementary Table 3.

\section{Material property measurement results}

The material properties of the 3D printed samples are shown in the Table 2. Masses of all PLA samples, which can be used to calculate the densities and to predict mechanical properties, fluctuated inconsistently as the number of TCs increased. The mass of a specimen is a reliable indicator of its tensile strength, and tensile strengths were observed to follow a similar fluctuating pattern. Only slight fluctuation of these parameters was detected with the PP specimens. The masses of the PLA samples were systematically larger than the masses of the PP samples, as expected, which is reflected in the mechanical property results. The filaments produced with the filament extruder had some inconsistency in their thicknesses, which ranged from $1.54 \mathrm{~mm}$ to $1.84 \mathrm{~mm}$, but the $3 \mathrm{D}$ printed objects expressed no notable dimensional inaccuracy. The densities of the specimens printed with all virgin materials ranged from 96 to $99 \%$, while the density reduced to as low as 74\% in the case of the thermally reprocessed PLA ReForm material. Complete tensile specimen data is presented in the Supplementary Tables 4 and 5.

Increase in the number of TCs had no directly observable effect on the alteration of mechanical properties of the studied materials (see the Supplementary Figs. 1 and 2).
Likewise to mass and density, both TS and EM fluctuated inconsistently after thermal reprocessing and the parameters did not express a consistent altering trend. An explicit trend was not observable even after the data was mass-normalized. The mass-normalization of the data was performed to reduce the impact of poor filament quality and the voids on the results, and to promote the impact of thermal degradation on the mechanical performance of the materials. Please see the Supplementary Tables 6 and 7 for normalized mechanical property data. However, the mass, density, TS and EM all followed a similar fluctuation pattern. A simple linear regression analysis of the complete data $(n=63)$ unveiled that the relative mass can accurately be used to predict both the value of TS $(p<0.01)$ and EM $(p<0.01)$. Furthermore, the TS and EM expressed a strong linear correlation (Pearson correlation, $\mathrm{p}<0.01, \mathrm{n}=63$, see the Supplementary Figs. 3, 4 and 5).

The virgin PLA sample TS values were comparable to those documented in literature. The average TS of the PLA Robotic Gray samples were reduced by $16 \%$ after 5 TCs after the data was normalized in accordance with mass, yielding expected values and negating the impact of 3D printing quality anomalies and voids. The normalization assumes an infill rate of $100 \%$ and thus, zero voids. For the average EM, the difference was $9 \%$. For the corresponding PLA ReForm samples the reductions were only $10 \%$ and $4 \%$, respectively. However, the measured EM values of the PLA materials were notably low overall, a meager 55-59\% of what is documented before. This implicates that the studied PLA materials were drastically more elastic and thus less rigid than those studied before. 
A contrary trend was found with the PP Transparent samples. The tensile specimen masses were notably reduced after $5 \mathrm{TCs}$, while the measured mechanical properties were virtually unchanged. The TS of the material was increased by $14 \%$ and EM as greatly as $33 \%$ after 5 TCs after the data was normalized. Simultaneously, the PP HWP material expressed $24 \%$ reduction in its TS and only $1 \%$ reduction in its EM after 3 TCs. The initially measured values were, however, far inferior in comparison to those documented in literature. The initially measured TS values were 53-79\% of previously reported values, while the EM values were $23-71 \%$ of what has been measured before. Surprisingly, the commercial PP Transparent expressed poor mechanical performance.

Both PLA filaments were effortlessly reprocessed four times. Challenges were encountered during the fifth cycle when the extruded filament became notably sticky. The stickiness resulted in blockages in the feeding and coiling systems of the filament extruder. The filament thickness was also more inconsistent after the $4^{\text {th }}$ cycle, which resulted in several failed prints before an ultimate success. No 3D printable filament could be produced after the fifth cycle. However, by personal monitoring of the filament production an unspecified amount of $3 \mathrm{D}$ printable filament could be produced. This was not proven in this study, however. The filament extruder was supposed to be an independent device, and its purpose would be defeated if it required constant monitoring. Henceforth, the fifth thermal cycle was the concluding point in this study.

Printing with both PP Transparent and PP HWP filaments was challenging as the printed objects were subject to considerable warping. 3D print jobs were successful when the printing platform was coated with a generic PP packaging tape. However, the PP Transparent material was easily reprocessed five times as it did not suffer from a notable reduction in its extrudability, unlike the PLA materials did. The PP HWP material on the other hand expressed similar behavior as the PLA materials and could be reprocessed only three times.

\section{Discussion}

As found to be consistent with previous studies, the observed 3D printing TVOC emission reduced as the number of TCs increased [34]. Similar trend was found with the UFP emissions, except during 3D printing with the PP HWP material where the effect was contrary. The evaporation and condensation of the most readily volatile compounds during the first cycles was the most likely cause of the highest initially measured concentrations [3, 7]. After the VOC emissions receded, the UFP emissions followed as nucleation capable matter reduced in the air phase [31, 35]. The TVOC emission concentrations of the studied polymer types evened out after one to two TCs, even though the differences between the PLA and PP materials were notable at first. The initially observed TVOC emission differences can be explained with the polymer base structure and the applied 3D printing temperature. The PP materials were printed at a higher temperature, which has a notable impact on 3D printing emissions $[13,22]$.

The main emitted chemical compounds were the same for both PLA filaments. However, even the most prevalent compounds were found in low concentrations. Additionally, these compounds do not pose a high risk, as they are not linked to acute or severe adverse health effects. However, both filaments expressed the accumulation of 1,4-dioxane, a CNS depressant and a probable human carcinogen, [43] as the number of TCs increased. The source of the compound was unclear, as there is no recorded evidence for the spontaneous formation of the compound during thermal reprocessing of PLA polymer. However, lactide, a common off-gassed compound encountered in thermal processing of PLA $[14,15]$ shares the same carbon-oxygen backbone with 1,4-dioxane, and the elimination of attached oxygen and carbon atoms could result in the formation of 1,4-dioxane. Another possible source for the compound was an unknown additive or other reactive degradation product that undergoes chemical transformation which ultimately results in the formation of 1,4-dioxane [44].

Another interesting finding was that the most prevalent compounds released during 3D printing with the PP materials were more diverse. Propylene glycol, a compound not linked to serious health risks, was the most prevalent compound and an evident outlier found during $3 \mathrm{D}$ printing with both filaments. It must be noted that the applied VOC collection method is best suitable for compounds that are 6 to 16 carbon atoms in length. Henceforth, portions of certain compounds, including propylene glycol, methacrolein, and propionaldehyde, may have passed through the sampling system. Therefore, the true concentrations of these compounds may have been greater than what is presented. In addition to propylene glycol, propionaldehyde was also detected during 3D printing with both PP filaments. However, certain other major compounds released during 3D printing with the PP materials were potentially harmful. 2-ethylhexanol expresses irritation and sensitizing potential, [45] while ethylbenzene and other hydrocarbons, e.g. xylene, possess irritation tendency along with CNS depressive and carcinogenic hazards [46]. Methacrolein is also a particularly hazardous chemical which can cause severe irritation of mucous membranes and the respiratory tract, CNS depression and sensitization [47].

The proposed lightweight UFP reference value of 40,000 $\# / \mathrm{cm}^{3}$ was not exceeded and henceforth the measured concentrations are considered to be relatively safe. However, it is plausible that even the measured concentrations can promote adverse health impacts, e.g., lung and cardiovascular 
effects, in prolonged exposure. This is due to the fact that the UFP dose-response relationship is practically linear [32, $33,35]$. The UFP exposure levels appeared to be concerning only when printing with the non-3D printing grade PP polymer, as the levels were low and receded further as the number of TCs increased when the 3D printing grade polymers were applied. As another note, the higher applied 3D printing temperatures of the PP filaments were certainly a major contributor for the higher UFP emissions [21-23]. Furthermore, as seen during 3D printing with the HWP material the UFP levels were increased notably after each TC. Interestingly enough, the increase in UFP emissions was observed simultaneously with decreases in the TVOC levels, while a contrary trend was observed with all other materials. Incomplete burning of the 3D printing material can attribute to the increased UFP emissions through the production and condensation of airborne polycyclic hydrocarbons and semivolatile compounds. These compounds are not detected by the applied chemical sampling method. This assumption can be supported by the further reduction in the filament quality during thermal reprocessing, which was poor to begin with. Irregular material feeding, clogging and slight material burning in the printing nozzle were observed during 3Dprinting. These are factors that drastically increase the UFP emissions. Additionally, it must be noted that the UFP reference value was designed for occupational health protection with a daily 8 -h exposure limit in mind, rather than for the preservation of the general populations. In occupational setting the exposure length is limited, and therefore reference value may not be a valid tool for assessing the exposure levels in non-industrial environments.

When certain material property enhancing compounds are disintegrated from the polymer structure the mechanical performance and the physical properties of the materials weaken $[1,2,4,5]$. These alterations leave the materials less useful for purposes where a $3 \mathrm{D}$ printed object is subject to mechanical stress, e.g., bending. However, 3D printed plastic objects are seldom used for particularly demanding purposes, as other methods of both traditional and additive manufacturing offer superior alternatives for purposes where the mechanical properties of an object truly matter. The disintegration of stabilizing agents may also expose the polymer for further chemical transformations where novel decomposition products can be formed [1, 2, 34].

Thermal treatment of polymers has been observed to reduce the molecular mass of the material, followed with decrease of mechanical properties [2,8]. It was found that the samples 3D printed with the virgin materials expressed the greatest mass in all cases, but the documented trends were not directly found even after the data was mass-normalized. The masses, densities, and mechanical properties were found to fluctuate as the number of TCs increased, and the trend was most distinguishable with the PLA materials.
Mass-normalization of the data negated the fluctuation effect to some extent but not decisively. The measured TS values of the PLA samples were initially only slightly lower than what is documented in literature. However, the measured EM values were greatly lower, almost half of the documented values. The lower EM values implicate that the PLA materials used in this study were notably more elastic than those documented in literature, which is plausible as the materials applied in this study were very likely treated with 3D printability enhancing additives for better extrudability. It must noted, however, that the referenced mechanical property values were pooled from various sources and the specimens tested in them did not completely match those tested in this study, and thus the results are not fully comparable.

The measured mechanical properties and the masses and the densities of the 3D printed samples had a connection between them. An alteration in the specimen mass was followed by a similar alteration in both TS and EM. This observation supports the claim which suggests that the relative mass or density of a material is one of the main determinants of its mechanical properties [2,8]. Additionally, the fluctuation of the mechanical properties in this study were most likely a result of the reduced 3D printability of the studied materials, which is a known side effect of thermal reprocessing of polymers [38]. While the filament extruder performed adequately in producing $3 \mathrm{D}$ printable filament, the thicknesses of the produced filaments were found to be inconsistent. The 3D printed objects will contain mechanical performance altering improperly filled voids if the thickness of the applied filament falls below the standard value of $1.75 \mathrm{~mm}$. This is what was expected to have occurred over the course of this study, as seen from the fluctuating pattern in mechanical properties and relative masses despite all samples being fabricated based on the same model and parameters. This assumption is supported by the mechanical property and mass measurements, as the virgin materials expressed the best mechanical properties, expect for the PP Transparent material. Even the PP HWP material expressed a similar trend which was found among the PLA materials, regardless of it not being a commercially produced 3D printing material to begin with. It can be stated that thermal reprocessing of 3D printing materials has a lesser impact on the mechanical properties of 3D printed objects than on the 3D printing filament integrity and quality. Recycled plastics can be used as 3D printing feedstocks without compromising mechanical performance if the applied filament is of adequate quality.

A simple regression analyses of the relationships between the tensile specimen masses and the measured mechanical properties, and a TS-EM correlation analysis were performed on the whole collected data. All these results were statistically significant $(\mathrm{p}<0.01)$, which further supports the claim that thermal reprocessing has little effect on the 
measured mechanical properties of PLA or PP plastics. However, thermal recycling has a more notable impact on the reprocessability itself, which was reflected as inconsistencies in the qualities of the filaments and ultimately in 3D printability, printing quality, and mechanical performance.

All PLA filaments maintained acceptable surface quality and adequate mechanical performance thorough the experiment. These materials were also lower VOC and UFP emitters and the listed findings promote PLA materials as a one of the best choices for material extrusion 3D printing. Even though the 3D printed PP objects were slightly poorer than the PLA objects in quality, the print jobs were successful. The recycled filaments filled their purpose for applications where the surface properties or dimensional accuracy of a printed object are not demanding. This suggests that even the recycled HWP materials are a plausible 3D printer feedstock alternative, even without introduction of 3D printability enhancing additives. Adhesion to the printing bed requires assistance, however.

\section{Conclusions}

The findings suggest that recycled 3D printing grade polymers are not particularly more hazardous to 3D print than virgin polymers. The concentrations of the most individual compounds decrease along with the TVOC concentration as the magnitude of thermal processing increases, which results in increasingly lower chemical exposure levels. Interestingly however, new compounds may be introduced into the VOC profile over thermal reprocessing and thus, unforeseen potential health hazards can emerge. A practical example is the accumulation of 1,4-dioxane in the studied PLA materials. It must be noted that the measured concentrations were low through the experiment and no acute health complications are expected to emerge from the use of recycled 3D printing filaments. Caution is advised especially when 3D printer filaments produced from non-3D printing grade polymers are applied, as the UFP levels were very high during printing with the PP HWP materials in comparison to the $3 \mathrm{D}$ printing grade materials. Nevertheless, basic 3D printing safety precautions, e.g., printing in a well-ventilated space and spending the least possible amount of time in the same space with a 3D printer should be always applied. These maneuvers notably reduce unnecessary exposure to the VOCs and UFPs emitted during a 3D printer operation.

Based on this study recycled plastics are a compelling feedstock alternative for virgin plastic materials for $3 \mathrm{D}$ printing. These materials can be applied on a large scale if a supply of such materials is developed. This is, given that the original polymer grade is suitable for an extrusion process. Household waste plastics, on the other hand, can be used for vanity purposes, as the material was found to be of meager quality and processability. Quite surprisingly, such a material was not found to be particularly hazardous. Further research on the factors affecting the mechanical, thermal, and polymer properties and the micro-scale alterations that influence $3 \mathrm{D}$ printability of thermally reprocessed polymers is recommended. Additionally, the effects of polymer blending should also be studied further as polymer cross-contamination is inevitable when polymer recycling is performed on a large scale. The understanding of these factors will substantially benefit in the development of more sustainable $3 \mathrm{D}$ printing materials.

Supplementary information The online version contains supplementary material available at https://doi.org/10.1007/s10965-021-02723-7.

Acknowledgements The authors would like to thank Ph.D. Kimmo Laitinen from the Department of Applied Physics of the University of Eastern Finland for technical assistance in mechanical property testing and M.A. Ari-Pekka Väisänen for proof-reading the manuscript.

Funding Open access funding provided by University of Eastern Finland (UEF) including Kuopio University Hospital. The study was supported by the OLVI Foundation under research grant number 201910391.

\section{Declarations}

Conflict of interest The authors declare no conflicts of financial or non-financial competing interest.

Open Access This article is licensed under a Creative Commons Attribution 4.0 International License, which permits use, sharing, adaptation, distribution and reproduction in any medium or format, as long as you give appropriate credit to the original author(s) and the source, provide a link to the Creative Commons licence, and indicate if changes were made. The images or other third party material in this article are included in the article's Creative Commons licence, unless indicated otherwise in a credit line to the material. If material is not included in the article's Creative Commons licence and your intended use is not permitted by statutory regulation or exceeds the permitted use, you will need to obtain permission directly from the copyright holder. To view a copy of this licence, visit http://creativecommons.org/licenses/by/4.0/.

\section{References}

1. Posṕíšil J, Horák Z, Kruliš Z, Nešpůrek S, Kuroda S-I (1999) Degradation and aging of polymer blends I. Thermomechanical and thermal degradation. Polym Degrad Stabil 65(3):405-414. https://doi.org/10.1016/S0141-3910(99)00029-4

2. Kutz M (2018) Handbook of environmental degradation of materials, 3rd edn. Elsevier, Amsterdam, Netherlands

3. Murata K, Hirano Y, Sakata Y, Uddin MA (2002) Basic study on a continuous flow reactor for thermal degradation of polymers. J Anal Appl Pyrolysis 65(1):71-90. https://doi.org/10.1016/j.jaap. 2009.08.009

4. Alex A, Ilango NK, Ghosh P (2018) Comparative role of chain scission and solvation in the biodegradation of polylactic acid (PLA). J Phys Chem B 122(41):9516-9526. https://doi.org/10. 1021/jp500219j 
5. Żenkiewicz M, Richert J, Rytlewski P, Moracziewski K, Stepczyńska M, Karasiewicz T (2009) Characterisation of multiextruded poly(lactic acid). Polym Test 28(4):412-418. https://doi. org/10.1016/j.polymertesting.2009.01.012

6. Garlotta D (2001) A literature review of poly(lactic acid). J Polym Environ 9(2):63-84. https://doi.org/10.1023/A:1020200822435

7. Andersson T, Stålblom B, Wesslén B (2004) Degradation of polyethylene during extrusion. II. Degradation of low-density polyethylene, linear low-density polyethylene, and high-density polyethylene in film extrusion. J Appl Polym Sci 91(3):1525-1537. https://doi.org/10.1002/app.13024

8. Tanikella NG, Wittbrodt B, Pearce JM (2017) Tensile strength of commercial polymer materials for fused filament fabrication 3D printing. Addit Manuf 15:40-47. https://doi.org/10.1016/j.addma. 2017.03.005

9. Tymrak BM, Kreiger M, Pearce JM (2014) Mechanical properties of components fabricated with open-source 3-D printers under realistic environmental conditions. Mater Des 58:242-246. https:// doi.org/10.1016/j.matdes.2014.02.038

10. Lechter T, Waytashek M (2015) Material property testing of 3D-printed specimen in PLA on an entry-level 3D printer. ASME 2014 International Mechanical Engineering Congress and Exposition Volume 2A: Advanced Manufacturing. Montreal, Quebec, Canada. https://doi.org/10.1115/IMECE2014-39379

11. Lanzotti A, Grasso M, Staiano G, Martorelli M (2015) The impact of process parameters on mechanical properties of parts fabricated in PLA with an open-source 3-D printer. Rapid Prototyp J 21(5):604-617. https://doi.org/10.1108/RPJ-09-2014-0135

12. Wittbrodt B, Pearce JM (2015) The effects of PLA color on material properties of 3-D printed components. Addit Manuf 8:110 116. https://doi.org/10.1016/j.addma.2015.09.006

13. Mendes L, Kangas A, Kukko K et al (2017) Characterization of emissions from a desktop 3D printer. J Indust Ecol 14:94-106. https://doi.org/10.1111/jiec.12569

14. Azimi P, Zhao D, Pouzet C, Crain NE, Stephens B (2016) Emissions of ultrafine particles and volatile organic compounds from commercially available desktop three-dimensional printers with multiple filaments. Environ Sci Technol 50(3):1260-1268. https:// doi.org/10.1021/acs.est.5b04983

15. Floyd EL, Wang J, Regens JL (2017) Fume emissions from a low-cost 3-D printer with various filaments. J Occup Environ Hyg 14(7):523-533. https://doi.org/10.1080/15459624.2017.1302587

16. Steinle $P$ (2016) Characterization of emissions from a desktop 3D printer and indoor air measurements in office settings. J Occup Environ Hyg 13(2):121-132. https://doi.org/10.1080/15459624. 2015.1091957

17. Stefaniak AB, LeBouf RF, Yi J et al (2017) Characterization of chemical contaminants generated by a desktop fused deposition modeling 3-dimensional printer. J Occup Environ Hyg 14(7):540 550. https://doi.org/10.1080/15459624.2017.1302589

18. Kim Y, Yoon C, Ham S et al (2015) Emissions of nanoparticles and gaseous material from 3D printer operation. Environ Sci Technol 49(20):12044-12053. https://doi.org/10.1021/acs.est. 5 b02805

19. Väisänen AJK, Alonen L, Ylönen S, Hyttinen M (2019) Occupational exposure to gaseous and particulate contaminants originating from additive manufacturing of liquid, powdered and filament plastic materials and related post-processes. J Occup Environ Hyg 16(3):258-271. https://doi.org/10.1080/15459624.2018.1557784

20. Sogancioglu M, Ahmetli G, Yel E (2017) A comparative study on waste plastic pyrolysis liquid products quantity and energy recovery potential. Energy Procedia 118:221-226. https://doi.org/ 10.1016/j.egypro.2017.07.020

21. Stephens B, Azimi P, El Orch Z, Ramos T (2013) Ultrafine particle emissions from desktop 3D printers. Atmos Environ 79:334339. https://doi.org/10.1016/j.atmosenv.2013.06.050
22. Yi J, LeBouf RF, Duling MG et al (2016) Emission of particulate matter from a desktop three-dimensional (3D) printer. J Toxicol Environ Health A 79(11):453-465. https://doi.org/10.1080/15287394.2016. 1166467

23. Zhang Q, Wong JPS, Davis AY, Black MS, Weber RJ (2017) Characterization of particle emissions from consumer fused deposition modeling 3D printers. Aer Sci Technol 51(11):1275-1286. https:// doi.org/10.1080/02786826.2017.1342029

24. Vance ME, Pegues V, van Montfrans S, Leng W, Marr LC (2017) Aerosol emissions from fuse-deposition modeling 3D printers in a chamber and in real indoor environments. Environ Sci Technol 51(17):9516-9523. https://doi.org/10.1021/acs.est.7b01546

25. House R, Rajaram N, Tarlo SM (2017) Case report of asthma associated with 3D printing. Occup Med 67(8):652-654. https:// doi.org/10.1093/occmed/kqx129

26. Chan FL, House R, Kudla I, Lipszyc JC, Rajaram N, Tarlo SM (2018) Health survey of employees regularly using 3D printers. Occup Med 68(3):211-214. https://doi.org/10.1093/occmed/ kqy042

27. Unwin J, Coldwell MR, Keen C, McAlinden JJ (2013) Airborne emissions of carcinogens and respiratory sensitizers during thermal processing of plastics. Ann Occup Hyg 57(3):399-406. https://doi.org/10.1093/annhyg/mes078

28. Win-Shwe T-T, Fujimaki H, Arashidani K, Kunugita N (2013) Indoor volatile organic compounds and chemical sensitivity reactions. Clin Dev Immunol 2013;2013:623812. https://doi.org/10.1155/2013/ 623812

29. Tuomi T, Vainiotalo S (2014) The guideline and target values for total volatile organic compound concentrations in industrial indoor environments in Finland. Ind Built Env 25(2):434-434. https://doi.org/10.1177/1420326X14554270

30. Savonius B, Keskinen H, Tuppurainen M, Kanerva L (1993) Occupational respiratory disease caused by acrylates. Clin Exp Allergy 23(5):416-424. https://doi.org/10.1111/j.1365-2222.1993. tb00348.x

31. Wang Z-M, Wagner J, Wall S (2010) Characterization of laser printer nanoparticle and VOC emissions, formation mechanisms, and strategies to reduce airborne exposures. Aer Sci Technol 45(9):1060-1068. https://doi.org/10.1080/02786826. 2011.580799

32. Pope CA, Dockery DW (2006) Health effects of fine particulate air pollution: lines that connect. J Air Waste Manag Assoc 56(6):709 742. https://doi.org/10.1080/10473289.2006.10464485

33. Mossman BT, Borm PJ, Castranova V, Costa DL, Donaldson K, Kleeberger SR (2007) Mechanisms of action of inhaled fibers, particles and nanoparticles in lung and cardiovascular diseases. Part Fibre Toxicol 4:4. https://doi.org/10.1186/1743-8977-4-4

34. Mylläri V, Hartikainen S, Poliakova V et al (2016) Detergent impurity effect on recycled HDPE: Properties after repetitive processing. J Appl Polym Sci 133:43766. https://doi.org/10.1002/app.43766

35. van Broekhuizen P, van Veelen W, Streekstra WH, Schulte P, Reijnders L (2012) Exposure limits for nanoparticles: report of an international workshop on nano reference values. Ann Occup Hyg 56(5):515-524. https://doi.org/10.1093/annhyg/mes043

36. Cicala G, Giordano D, Tosto C, Filippone G, Recca A, Blanco I (2018) Polylactide (PLA) filaments a biobased solution for additive manufacturing: correlating rheology and thermomechanical properties with printing quality. Materials 11(7):1191. https://doi. org/10.3390/ma11071191

37. Raj SA, Muthukumaran E, Jayakrishna K (2018) A case study of 3D printed PLA and its mechanical properties. Mater Today Proc 5(5):11219-11226. https://doi.org/10.1016/j.matpr.2018.01.146

38. Anderson I (2017) Mechanical properties of specimens 3D printed with virgin and recycled polylactic acid. 3D Print Addit Manuf 4(2):110-115. https://doi.org/10.1089/3dp.2016.0054 
39. Carneiro OS, Silva AF, Gomes R (2015) Fused deposition modeling with polypropylene. Mater Des 83:768-776. https://doi.org/ 10.1016/j.matdes.2015.06.053

40. Zander NE, Gillan M, Burckhard Z, Gardea F (2019) Recycled polypropylene blends as novel 3D printing materials. Addit Manuf 25:122-130. https://doi.org/10.1016/j.addma.2018.11.009

41. Milosevic M, Stoof D, Pickering KL (2017) Characterizing the mechanical properties of fused deposition modelling natural fiber recycled propylene composites. J Compos Sci 1(1):7. https://doi. org $/ 10.3390 /$ jcs 1010007

42. Kaynak B, Spoerk M, Shirole A, Ziegler W, Sapkota J (2018) Polypropylene/cellulose composites for material extrusion additive manufacturing. J Macromol Mater Eng 303:1800037. https:// doi.org/10.1002/mame.201800037

43. International Agency for Research on Cancer (IARC) (1999) IARC monographs on the evaluation of carcinogenic risks to humans. Re-evaluation of some organic chemicals, hydrazine and hydrogen peroxide, WHO, Geneva, Switzerland, vol 71, pp 589-602.
44. U.S. Environmental Protection Agency (2017) Preliminary information on manufacturing, processing, distribution, use and disposal: 1,4-Dioxane. Support document for Docket EPA-HQOPPT-2016-0723 (2017). Available at:https://www.epa.gov/sites/ production/files/2017-02/documents/14-dioxane.pdf. Accessed 3 Oct 2020

45. Wakayama T, Ito Y, Miyake M, Shibata E, Ohno H, Kamijima M (2019) Comprehensive review of 2-ethyl-1-hexanol as an indoor air pollutant. J Occup Health 61(1):19-35. https://doi.org/10. 1002/1348-9585.12017

46. Malachowski MJ, Goldberg AF (1999) Health effects of toxic substances, 2nd Edition. Government Institutes, Rockville, Maryland, USA

47. Larsen ST, Nielsen GD (2000) Effects of methacrolein on the respiratory tract in mice. Toxicol Lett 114(1-3):197-202. https:// doi.org/10.1016/S0378-4274(99)00300-8

Publisher's Note Springer Nature remains neutral with regard to jurisdictional claims in published maps and institutional affiliations. 